\title{
AS POLÍTICAS PÚBLICAS NA CONJUNTURA DO DESENVOLVIMENTO RURAL E MANUTENÇÃO DA AGRICULTURA FAMILIAR: PARADIGMAS, DESAFIOS E CONTROVÉRSIAS
}

\author{
THE PUBLIC POLICIES AT CONJUNCTURE OF RURAL DEVELOPMENT AND \\ MAINTENANCE OF THE FAMILY FARMING: PARADIGMS, CHALLENGES AND \\ DISPUTES
}

\author{
Dayana Lilian Rosa Miranda ${ }^{1}$ \\ Pedro Martins ${ }^{2}$
}

\section{RESUMO}

A presente investigação pretende discutir a problemática de agricultores familiares tradicionais que tiveram sua atividade fragilizada pela dinâmica produtiva dominante instalada na época da modernização da agricultura e hoje apresentam sérias dificuldades em manter-se na terra, produzindo seus alimentos para subsistência ou, quiçá, para comercialização. Sendo assim, busca-se avaliar a partir da visão dos sujeitos, a relação das políticas públicas direcionadas ao desenvolvimento da agricultura familiar relacionadas ao paradigma do desenvolvimento rural e à manutenção da atividade no território do Vale do Ribeira - Paraná, mais especificamente nos municípios de Rio Branco do Sul e Itaperuçu, com vistas a verificar a referida contribuição destas políticas públicas no contexto do desenvolvimento rural e cumprimento dos objetivos propostos. Assim, pode-se concluir que a agricultura familiar tem relevância no alcance do desenvolvimento rural e sustentável do meio, mas este êxito é dependente das políticas públicas.

Palavras-chave: Território, Políticas Públicas, Agricultura Familiar, Desenvolvimento Rural.

\section{ABSTRACT}

This research aims to discuss the problematic of traditional family farmings that had their activity weakened by the dominant productive dynamics installed in the agriculture modernization times and currently presents serious difficulties about keeping up the land, producing food for their subsistence or perhaps for sale. Thus, the goal is to evaluate from the perspective of the subjects, the public policies relation aimed at the development of family farming, linked to the paradigm of rural development and maintenance activity in Ribeira Valley- Paraná territory, more specifically in Rio Branco do Sul and Itaperuçu municipalities, with the purpose of verify the public policies contribution for the rural development context

\footnotetext{
${ }^{1}$ Mestra em Planejamento Territorial e Desenvolvimento Socioambiental pela Universidade do Estado de Santa Catarina - UDESC (2013/15) do departamento de Geografia e Bacharel em Turismo pela Universidade Federal do Paraná - UFPR (2007/11). E-mail: dayana.1.rosa@gmail.com.

2 Professor Associado da Universidade do Estado de Santa Catarina-UDESC. Endereço: Avenida Madre Benvenuta, 2007 - Itacorubi, Florianópolis - SC, 88035-001. Telefone: (48) 3664-8000. Tem doutorado em Antropologia Social pela Universidade de São Paulo (2001) e atua como professor e pesquisador do Programa de Pós-Graduação em Planejamento Territorial e Desenvolvimento Socioambiental/ PPGPLAN. É membro da Associação Brasileira de Antropologia/ABA e Diretor Científico do Instituto Egon Schaden /IES. Coordena o Grupo de Pesquisa Práticas Interdisciplinares em Sociabilidades e Territórios - PEST/UDESC. E-mail: weltermartins@yahoo.com.br.
} 
and achieving desired objectives. Thus, we can conclude that the family farming has relevant to achievement of rural and sustainable environment development, but this success is dependent of the public policies.

Keywords: Planning, Public Policies, Family Farming, Rural Development.

\section{Introdução}

Este trabalho pretende discutir os referenciais metodológicos e teórico-temáticos que deram base à pesquisa intitulada "Políticas Públicas para a Agricultura Familiar na Visão dos Sujeitos: uma incursão no Vale do Ribeira - Paraná” desenvolvida no âmbito do PPGPLANUDESC. É proposto, portanto, um breve resgate da literatura produzida relacionada ao panorama agrícola nacional e aos embates sociopolíticos em torno do desenvolvimento rural a partir da modernização da agricultura brasileira a fim de dar sustentação ao arcabouço teórico referente à discussão acerca da temática agricultura familiar e políticas públicas, correlacionadas, portanto, ao desenvolvimento rural e, consequentemente, ao objeto de estudo enfocado.

Ao que segue, antes disso considera-se importante apresentar o objeto de estudo enfocado que antecede o direcionamento dado ao presente estudo a fim de elucidar pontos importantes e a contextualização a ser considerada para o desenvolvimento da presente abordagem.

Sendo assim, em se tratando especificamente do Vale do Ribeira - Paraná, nota-se a importância da agricultura familiar tradicional e cabocla para a região tendo em vista que esta foi a forma de produção e trabalho pela qual se territorializou e se apropriou historicamente do espaço rural. Este fator instiga a pesquisa sobre o processo de mudança da estrutura das atividades econômicas, do emprego, das relações ambientais, sociais e culturais ocorridas no processo com o passar do tempo.

A partir das transformações técnicas e produtivas decorrentes da modernização da agricultura - década de 1970 - os agricultores familiares locais, sem outra opção, se inseriram crescentemente na dinâmica do mercado, caracterizada pela implementação e disseminação da atividade de silvicultura ou megassilvicultura - monocultura extensiva do Pinus Elliottii (Engelm) e do Eucalyptus Saligna (Sm), acarretando em uma realidade social complexa e multifacetada que envolve atualmente os remanescentes de agricultores de origem familiar e sua reprodução social. Em decorrência, o processo em foco fez com que muitos agricultores familiares perdessem a autonomia do processo produtivo e a tradição do saber fazer e 
produzir os seus próprios alimentos, levando uma considerável parcela desses agricultores a um evento contínuo de abandono das áreas rurais, mudança nas relações de trabalho e vulnerabilização da identidade cultural trazendo, como consequência, a perda gradativa de autonomia frente ao contexto socioeconômico então instalado no território.

Por sua vez, os municípios de Rio Branco do Sul e Itaperuçu - PR foram os dois municípios, dentre os sete que compõem o Vale do Ribeira paranaense, que mais sofreram impactos na atividade agrícola com a instalação da megassilvicultura no território, dada a sua proximidade com a capital do Estado, Curitiba, representando, portanto, o recorte do objeto de estudo.

No contexto geral da problemática de pesquisa, entende-se que existe a necessidade de que as políticas públicas atuais direcionem esforços efetivos em prol do desenvolvimento rural do território e da mudança deste tipo de "desenvolvimento instalado", com efetiva participação dos atores envolvidos, para que esta situação de vulnerabilidade dos agricultores familiares não atinja níveis em que as problemáticas sociais, econômicas e ambientais tornem-se ainda mais graves.

Assim, busca-se na pesquisa em foco analisar as políticas públicas relacionadas ao apoio e manutenção da agricultura familiar atualmente em vigência nos municípios de Rio Branco do Sul e Itaperuçu, com vistas a verificar a referida contribuição no contexto do desenvolvimento territorial e sustentável do meio rural e o cumprimento dos objetivos propostos.

Sendo assim, este texto abordará basicamente o referencial teórico-temático e algumas conclusões preliminares do estudo que permitirão o aprofundamento da compreensão da dinâmica do tema.

\section{Paradigmas da modernização em questão.}

Tomando por base a obra de Silva (2003), nascia nos anos 1950 no Brasil um planejamento sistemático da economia pautado nas missões econômicas norte-americanas realizadas no país no final da década de 1940 - no contexto do projeto nacionalista de Getúlio Vargas e na estratégia de desenvolvimento pensada pela Comissão Econômica para América Latina - CEPAL. A estratégia baseava-se na promoção de matéria-prima por conta do setor agrícola nacional visando o desenvolvimento da indústria e a consequente redução das importações, vindo então a agricultura "sustentar" a crescente população urbana no Brasil 
assim como gerar receitas cambiais através de exportações de produtos primários. Sob a ótica de Bosseti (2013) a ideia era que a agricultura desempenhasse um papel subsidiário na industrialização do país gerando divisas no campo da exportação, alimentos baratos no mercado interno e, ainda, se constituísse em um mercado consumidor de artigos industriais.

Porém, a dimensão da problemática tornava-se maior do que a insuficiência da oferta interna de alimentos, seus efeitos sobre os saldos cambiais e os custos da produção industrial, pois a burguesia industrial defendia a necessidade de ampliação do mercado interno para assegurar o consumo das indústrias nascentes - produtos manufaturados, sem levar em consideração que a produção capitalista não se dá tanto em função dos bens de consumo final, mas sim dos meios de produção (SILVA, 2003), ou seja, a necessidade de insumos, matériasprimas, mão de obra, maquinário, construções, entre outros, gerando uma verdadeira "produção para produção" - era a chamada internalização do setor produtor de capital - D1 (utilizava-se o termo D1 para definir o conjunto de setores produtores de bens de capital e insumos).

Consolida-se, então, nos anos 1960 o início da industrialização/modernização da agricultura no Brasil, gerando desta forma o que podemos chamar de divisão social do trabalho e de transformação das condições dos agricultores em operários assalariados do capitalismo, caracterizando uma perda gradativa da auto-suficiência agrícola de que dispunha o meio rural em substituição dos meios de produção como máquinas e insumos para o campo (SILVA, 2003). Na concepção de Garcia Jr. \& Grynszpan (1999) a organização produtiva e os circuitos comerciais foram estruturados de tal modo que à formação social brasileira caberia sempre um papel subordinado na divisão internacional do trabalho: a emancipação do Brasil contemporâneo encontrava seu limite na herança do Brasil colonial.

Por sua vez, a década de 1970 acusa uma realidade nacional voltada para a agroindústria, sob o domínio do capital industrial e financeiro e ao processo global de acumulação, marcando assim a fase de constituição dos complexos agroindustriais (CAIs), como define Silva (2003), sob a forma de junção e concentração de capitais industriais, dando origem, portanto, às associações limitadas, cooperativas rurais, sociedades anônimas, entre outras. Segundo o autor, este fato marca o início de uma forte concentração de propriedade da terra onde a evolução da estrutura fundiária no país é reafirmada no sentido concentrador e excludente. 
Guimarães (1977) considerou o latifúndio brasileiro como a herança de uma estrutura feudal constituída no Brasil durante o período colonial. Destaca que o latifúndio e o Brasil nasceram praticamente juntos, dada a implantação das capitanias hereditárias e a concessão de terras que formou a ocupação do território, juntamente com a herança cultural que moldou a estrutura sociológica e histórica e favoreceu a manutenção de uma concentração de terra que pendura até os dias atuais. Ele defende que, mesmo com a ascensão do capitalismo, a lógica ainda não havia sido rompida, pois as relações sociais de produção no campo continuavam sendo coloniais. A mesma linha de raciocínio é defendida por autores como Antônio Cândido (1977), José de Souza Martins (1986) e Caio Prado Junior (1979), que reiteram a afirmativa de que ao longo da história da agricultura brasileira a distribuição desigual da propriedade da terra é fato determinante para o acentuado grau de concentração da propriedade fundiária, o que caracteriza a generalidade da estrutura agrária brasileira contemporânea.

Como consequência, junto ao processo de difusão da modernização do setor agrícola ocorre um processo de especialização da agricultura em escala nacional (BALSAN, 2006). Silva (2003) mostra como, dado o foco da produção ser voltado à exportação, aqueles produtos mais valorizados para este fim propiciaram ao país um processo de modernização e crescimento econômico do setor, porém de forma espacializada, ocorrendo pontualmente em determinados locais e regiões, considerados na época como prioritários os principais centros econômicos do país, ao passo que deixava outras regiões à margem do processo. As alterações no modo de produzir e organizar a produção agrícola nacional incitou então uma reorganização do espaço geográfico, adequando-o às novas condições de produção definidas, em geral, pelos interesses do Estado e dos grandes grupos econômicos capitalistas.

Na visão de Almeida (1997) a integração da agricultura à indústria não significa, simplesmente, uma mudança de ordem quantitativa (comprar, produzir e vender mais), mas também uma transformação radical das estruturas internas do país (espaciais, de produção e comercialização, assim como sociais).

Silva (2003) afirma que as condições econômicas, sociais e políticas impostas pela modernização agrícola brasileira indicam disparidade entre diferentes classes sociais, marginalizando diretamente os grupos menos favorecidos, como os agricultores com baixo poder aquisitivo, pequenos proprietários e agricultores familiares.

Relacionado especificamente à agricultura familiar, Bossetti (2013) acredita que tais problemas foram originados na época devido ao fato de que os agricultores de base familiar, 
que antes já tinham dificuldades de acessar o crédito, sofreram ainda mais com a redução de sua oferta e, assim, não modernizaram suas propriedades. Por outro lado, grande parcela daqueles agricultores familiares que conseguiram acessar o crédito acabaram endividados diante da inflação e das taxas de juros elevadas.

Souza et al. (2006) mencionam que, devido ao baixo nível de avanço tecnológico, a agricultura familiar de pequeno porte ainda se apresenta com baixos níveis de desenvolvimento e "problemas tanto de caráter produtivo (baixa capacidade de produção, mecanização inadequada, terras insuficientes) [...]" quanto de caráter organizativo e técnico.

Assim, a modernização da agricultura no Brasil se deu de forma progressiva e pontual, marcando diferenças estruturais e espaciais no meio rural, assim como na produção agrícola.

Em suma, pode-se dizer que esse período deixou marcas que até hoje não foram superadas, causadas pelos interesses dominantes do estilo de desenvolvimento adotado, vindo a provocar resultados sociais, econômicos e ambientais desastrosos. A exemplo, podemos citar a concentração fundiária, o êxodo rural, a exploração da mão-de-obra no campo, a concentração de renda, a influência dos complexos agroindustriais, as diferenças tecnológicas, o aumento generalizado da pobreza no campo, a destruição das florestas e derrubada de mata nativa, a redução e/ou perda da biodiversidade e da capacidade produtiva do solo, a contaminação dos recursos naturais, a dependência química na produção dos alimentos, entre outros sérios danos sociais, econômicos e ambientais que geraram, portanto, mais desigualdade social no meio rural e substanciais dificuldades para o homem do campo manter-se na terra.

Neste sentido, nota-se o fato de que as tendências dessa "nova agricultura" que emergiu da modernização da atividade, gerando esta nova dinâmica no meio rural, revelam uma realidade em que, ao passo que trouxe de fato a modernização da agricultura nacional à grande propriedade, com novas tecnologias para o campo - ainda que de forma espacializada e pontual, trouxe também ao pequeno agricultor ou agricultor familiar um distanciamento dessas inovações, impondo à categoria inúmeras e crescentes limitações nas estratégias de produção, colocando-os à margem da dinâmica da atividade agrícola nacional.

Nota-se, portanto, que a intervenção do Estado, por meio das políticas públicas, levou a agricultura a se modernizar e a incorporar crescentemente os recursos tecnológicos 
surgidos nesse período - os quais constituem o cerne das transformações técnico produtivas e da penetração do capitalismo no campo.

Silva (2005), a este respeito, afirma que os efeitos dos programas implantados anteriormente influenciam os resultados de ações públicas em curso, sendo a abordagem histórica da intervenção governamental e seus efeitos, da trajetória da população e das transformações na ocupação dos territórios, de grande importância na avaliação de programas e políticas direcionadas para o desenvolvimento rural.

\section{Alternativas para o desenvolvimento rural}

Abramovay (1998) defende que o desenvolvimento rural não acontecerá espontaneamente como resultado da dinâmica das forças de mercado, mas sim da elaboração de políticas capazes de promovê-lo. Na visão do autor, a valorização da agricultura familiar e o reconhecimento de seu potencial dinamizador das economias locais é o ponto principal de discussão. Em consonância com o exposto, Cazella (2012) entende que, para que a inserção produtiva seja possível, mudanças de rumo precisam ser feitas nas principais políticas públicas de desenvolvimento rural.

Neste sentido, na essência da presente investigação, defende-se a ideia de que as políticas públicas ligadas à manutenção e desenvolvimento da agricultura familiar estejam direcionadas única e exclusivamente para este fim, rompendo com a lógica adotada pelo Estado desde a modernização da agricultura, ou seja, a priorização de ações e estratégias governamentais voltadas ao agronegócio, unidades produtivas já inseridas na dinâmica produtiva do sistema e às políticas de cunho agrícola. É preciso quebrar paradigmas ligados à "ideologia modernizadora" e construir uma realidade na qual a agricultura deve ser enfocada a partir de diretrizes que não estejam voltadas apenas para a reprodução do capital e aos interesses dominantes.

Assim, vê-se que o futuro das ações institucionais ligadas à agricultura podem tomar duas frentes de atuação: continuar a trilhar o caminho de apoiar prioritariamente grandes unidades agrícolas voltadas à agroexportação e os estabelecimentos familiares já integrados nos mercados - deixando em segundo plano as iniciativas de inserção produtiva das situações de pobreza rural, ou, ao invés disso, fazer uma opção de médio prazo, visando à inserção social e produtiva de agricultores familiares historicamente excluídos das políticas públicas (CAZELLA, 2012). 
No que tange às políticas agrícolas impulsionadas pelo Governo Federal na década de 1990 e primórdios do século XXI, elas marcam o início de uma época caracterizada por iniciativas importantes voltadas ao fortalecimento dos pequenos agricultores.

Segundo Gazolla (2004), algumas ações ocorreram sob um contexto de mudança favorável em torno da segurança alimentar e nutricional das classes menos favorecidas, abrangendo novas dimensões políticas e sociais no país.

Bonnal \& Kato (2011) citam como a maior visibilidade da necessidade de reconhecimento das especificidades da agricultura familiar a criação do Ministério do Desenvolvimento Agrário (MDA), em 1999, constituindo-se uma importante iniciativa para a formulação e implementação de políticas públicas diferenciadas para a agricultura familiar e comunidades tradicionais. Seguiu-se a aprovação, em 2006, da Política Nacional da Agricultura Familiar e Empreendimentos Familiares Rurais, que trouxe um reconhecimento político à categoria produtiva, estabelecendo conceitos, princípios e instrumentos para a formulação de políticas públicas voltadas à agricultura familiar.

Na visão de Gazolla (2004), o Programa Nacional de Fortalecimento da Agricultura Familiar - PRONAF inaugura uma nova fase importantíssima voltada à agricultura familiar brasileira, onde os agricultores familiares se tornam alvos de políticas públicas e atores sociais demostrando, assim, o Estado, a importância da categoria para o desenvolvimento do país.

Guanziroli (2007) destaca que o PRONAF surge com o propósito de subsidiar crédito aos agricultores, em particular os familiares, numa época em que o elevado custo e a escassez de crédito eram apontados como os principais problemas. $\mathrm{O}$ autor nota que, após 10 anos de execução, o programa se estendeu de forma considerável por todo o território nacional, ampliou o montante financiado, impulsionou programas, assumiu a assistência técnica e reforçou a infraestrutura tanto dos próprios agricultores quanto dos municípios abrangidos.

Já Petrelli \& Silva (2004) ressaltam que o PRONAF estaria privilegiando, na verdade, a propriedade familiar "eficiente" em detrimento das mais fragilizadas em observância ao fato de que, no leque do universo considerado, são os agricultores familiares o grupo mais integrado do ponto de vista econômico. Os autores observam, também, a elevada proporção do financiamento para o fumo e a soja - produtos destinados à produção agroindustrial e de exportação - em relação ao total financiado, ao passo que verificam a baixa 
proporção de liberação de recursos para a produção de arroz, feijão e outros produtos dirigidos ao mercado interno.

$\mathrm{Na}$ visão de Sabourin (2007), ainda que os créditos para a agricultura familiar tenham aumentado muito e sejam distribuídos segundo diversas modalidades, apenas representam de $15 \%$ a $20 \%$ daqueles destinados à agricultura patronal. O autor defende ainda que o PRONAF, sob a forma de crédito individual ou de subvenção para equipamentos coletivos, beneficiou, sobretudo, os agricultores familiares mais dotados de capital, melhor articulados com a rede bancária e de forma espacializada, beneficiando essencialmente a região Sul.

Cazella (2012), analisando alguns precedentes sobre o desempenho e a capacidade do PRONAF em beneficiar agricultores familiares, conclui que a orientação do Programa se deu em vias de atender unidades familiares com melhor desempenho produtivo. Segundo o autor, a modalidade de microcrédito do Programa apresentou resultados pífios com diversas evidências de que não se trata de uma linha estratégica dentro desse Ministério.

Em relação às políticas públicas para a promoção do desenvolvimento rural em sua generalidade, destaca-se que o próprio governo brasileiro admite o fato de que as políticas públicas implementadas nas últimas décadas no Brasil foram insuficientes ou não foram efetivamente focadas no objetivo de generalizar melhorias substanciais na qualidade de vida e nas oportunidades de prosperidade das populações que habitavam o interior brasileiro (MDA, 2003).

Na visão de Leite \& Delgado (2011), na atualidade, o direcionamento que preside as políticas públicas voltadas para a agricultura no Brasil tem estimulado o desenvolvimento de uma agricultura empresarial que tende a reproduzir um modelo de desenvolvimento cujas raízes se fincam no padrão agroexportador que se sustenta desde o período colonial.

Freitas et al. (2010) chamam a atenção para o fato de que as políticas públicas implementadas nas últimas décadas para promoção do desenvolvimento rural no Brasil tomaram como base uma representação do rural como agrícola, onde o crescimento substancial da produtividade deveria ser estimulado em função do crescimento econômico.

Nota-se, todavia, que os investimentos no meio rural não foram efetivamente destinados ao objetivo de generalizar melhorias substanciais na qualidade de vida e nas oportunidades de prosperidade das populações que habitam e habitavam o interior brasileiro, mas sim ao agronegócio e grandes dinâmicas de exportação. 
Em suma, as políticas públicas atualmente praticadas pelo Estado brasileiro em relação à agricultura familiar continuam com a mesma lógica não rompendo, totalmente, com o padrão de desenvolvimento adotado pelo governo durante os anos de modernização agrícola.

Para enfrentar esses problemas, mudanças substanciais deverão ocorrer no escopo e na forma de encarar o desafio de resgatar da pobreza e do abandono a vasta população que atualmente enfrenta os velhos problemas que assolam o meio rural brasileiro.

Nota-se que novas concepções estão se formando a partir das múltiplas articulações que vem despertando os olhares de atenção para com o meio rural e de ações pautadas nas necessidades primordiais de integridade territorial, de preservação da biodiversidade e conservação dos recursos naturais, da valorização da identidade e cultura agrícola e da multiplicação de oportunidades de inclusão, preceitos estes que se traduzem na essência da presente investigação.

Neste sentido, não deixa de ser surpreendente a velocidade com que ganha espaço público e legitimação a assertiva de que é preciso repensar o modelo de desenvolvimento rural adotado no Brasil e, mais do que isto, reorientar as formas de intervenção do Estado e as políticas públicas (SCHNEIDER; TARTARUGA, 2005).

Leite \& Delgado (2011) ressaltam a necessidade de reconfigurar os campos de poder, sendo preciso avaliar bem os instrumentos disponíveis para tanto (como o fortalecimento das organizações locais) e o perfil de atores estratégicos com os quais se irá desenvolver o processo de gestão, sendo necessário dar visibilidade a atores mais vulneráveis para os quais se espera um acesso ao conjunto de políticas e recursos. Ou seja, é preciso pensar a dinâmica territorial de forma não autárquica, valorizando os procedimentos de desenvolvimento endógeno, o qual resultará numa gestão e governança mais complexa intra e inter territórios, bem como entre os diferentes níveis por onde circulam os atores.

\section{Desenvolvimento do meio rural, políticas públicas e demais questões agrárias}

Segundo Navarro (2001), durante muito tempo o desenvolvimento rural foi associado ao conjunto de ações do Estado e de organismos internacionais destinados a intervenções nas regiões rurais pobres que não conseguiam se integrar ao processo de modernização agrícola, preconizando ações de intervenção dirigidas e orientadas sob um caráter compensatório. 
Scheinder (2010) ratifica a ideia dizendo que a discussão corrente sobre o tema do desenvolvimento rural no Brasil vem sendo fortemente influenciada pelas ações de caráter normativo e pelas políticas de intervenção do Estado.

Ploeg et al. (2000) associam a modernização da agricultura e as políticas de compensação posteriores à fase ao termo "desenvolvimento rural" - visto como uma ferramenta para elevar a renda e o desenvolvimento das comunidades rurais. $\mathrm{Na}$ visão dos autores, o desenvolvimento rural implica na criação de novos produtos e novos serviços, associados a novos mercados. Implica também em uma tentativa de reconstrução da agricultura em termos regionais e da economia rural como um todo, representando "[...] uma saída para as limitações e a falta de perspectivas intrínsecas ao paradigma da modernização e ao acelerado aumento de escala e industrialização que ele impõe" (p. 395).

Entende-se por desenvolvimento rural a melhoria das condições de vida das pessoas residentes nas áreas e regiões rurais através de processos sociais que respeitem e articulem os princípios de eficiência econômica, equidade social e territorial, qualidade patrimonial e ambiental, sustentabilidade, participação democrática e responsabilidade cívica (MDA, 2003).

Atualmente, as políticas de desenvolvimento rural (ainda) apresentam a pobreza rural como principal escopo de ação, sob a forma de encarar o desafio de enfrentar a pobreza do meio rural como uma das maneiras de se delinear as táticas dos processos de desenvolvimento (MDA, 2003). Neste contexto, Freitas et al. (2010) lembram que estratégias para combater a pobreza no meio rural passaram a ser cruciais, apontando as políticas de desenvolvimento rural para o desenvolvimento territorial como um caminho para enfrentar a situação

Segundo Abramovay (2010), a pobreza rural não pode ser encarada como expressão de insuficiência na renda agropecuária, mas como fenômeno multidimensional.

Importante se faz pensar que as transformações ocorridas no meio rural implicam no fato de que as políticas públicas considerem que as zonas rurais têm necessidades novas, novas dinâmicas, novas demandas, novos contextos, típicos de uma sociedade moderna. Sob essa ótica, as políticas de desenvolvimento territorial devem trazer, a partir da diversidade de atuação, inovações em relação às políticas "do passado", tendo como premissa o desenvolvimento sustentável, a participação dos atores e o estímulo à coesão social e territorial.

Para Maluf (2001), a temática territorial permitiu a emergência, na definição de políticas públicas, de um discurso de revalorização do meio rural antes negligenciado em 
ações de desenvolvimento regional que eram basicamente voltadas para a estruturação dos espaços urbanos. Esta revalorização se deu com base no caráter multifuncional que a agricultura familiar estabelece com o território e sobre o qual o meio rural deixa de ser entendido somente por suas características produtivas e passa a ser valorizado também por seus aspectos sociais, culturais e ambientais.

Na concepção de Abramovay (2010) a abordagem territorial abre caminho para um avanço notável na concepção do estudo do desenvolvimento, visto a ênfase na maneira como os diferentes atores - públicos, privados e sociedade civil organizada - relacionam-se no plano local.

Estudos como os de Fox (1990), Navarro (1999, 2002) e Martins (1999, 2003), indicam que os processos de desenvolvimento ligados à diversidade de atuação podem e devem contribuir, efetivamente, para estimular a "emancipação social", criar mecanismos de responsabilização (accountability) e promover a democratização da sociedade, a participação dos atores e a coesão social e territorial.

$\mathrm{Na}$ presente proposta, partilha-se da ideia de que é inovador estimular o desenvolvimento endógeno dos territórios rurais, no sentido de orientar políticas públicas segundo as demandas expressadas pelas comunidades e organizações da sociedade, reconhecendo as especificidades de cada território e ofertando instrumentos de desenvolvimento que atendam a essas características.

\section{Considerações finais}

O ponto que perpassa a presente pesquisa é a visível necessidade emergencial de manutenção e desenvolvimento da agricultura familiar e de seu potencial como modelo social, econômico e produtivo. Trata-se de entender em que condições os pequenos produtores e suas organizações locais podem agir frente aos desafios colocados pela forma atual com que o capitalismo opera na agricultura e em seus modos de produção.

Em suma, acredita-se que os estudos sobre o desenvolvimento rural no Brasil precisam buscar uma maior emancipação relacionada ao modelo de desenvolvimento adotado a partir das ações do Estado, das políticas públicas e principalmente da participação social, em vias de atingir uma perspectiva real da necessidade emergencial dos processos de mudança social. 
Assim, a presente proposta toma por base a análise das políticas públicas locais a partir da visão dos sujeitos, dada a necessidade de análise mais profunda dos processos de mudança social do meio rural ao que se refere o objeto de estudo enfocado, em vias de verificar em que medida as diversas "forças" reconfiguram e afetam as relações com o espaço e o meio ambiente, e se contribuem ou não para a melhoria das condições de vida dos envolvidos.

Em suma, acredita-se que o planejamento e gestão dos territórios rurais precisam estar ancorados em um novo paradigma de desenvolvimento que permita rever as práticas atuais empregadas para o seu alcance, bem como a reorientação da economia de modo a refletir também as implicações sociais e ambientais das políticas direcionadas ao processo de desenvolvimento no meio rural. Este é sem duvida o grande desafio que se apresenta para o futuro, ou seja, harmonizar o desenvolvimento econômico, a qualidade ambiental e a soberania social.

\section{REFERÊNCIAS}

ABRAMOVAY, Ricardo. Agricultura Familiar e Desenvolvimento Territorial. Ruralia Revista da Association des Ruralistes Françaisv.2, n 3, pp. 91-111, março, 1998.

ABRAMOVAY, Ricardo. Para uma teoria dos estudos rurais. in: VIEIRA, Paulo et al. (org). Desenvolvimento Territorial Sustentável no Brasil: subsídios para uma política de fomento. Florianópolis: Secco, 2010. p.27-47.

ALMEIDA, Jalcione; NAVARRO, Zander (orgs.). Reconstruindo a Agricultura: ideias e ideais na perspectiva de um desenvolvimento rural sustentável. Porto Alegre: Editora da UFRGS, 1997.

BALSAN, Rosane. Impactos decorrentes da modernização da agricultura brasileira. Campoterritório: Revista de Geografia Agrária, v. 1, n. 2 p. 123-151, ago. 2006.

BRASIL. Ministério de Desenvolvimento Agrário (MDA). Referências para o Desenvolvimento Territorial Sustentável. Brasília: MDA/SDT, CONDRAF, 2003.

BONNAL, Philippe; KATO, Karina. O processo contemporâneo de territorialização de políticas e ações públicas no meio rural brasileiro. in: Políticas Públicas, Atores Sociais e Desenvolvimento Territorial no Brasil. Brasília: IICA, 2011. p. 61-82.

BOSETTI, Cleber José. Perspectivas de Desenvolvimento Rural em Disputa no Brasil. Tese de Doutorado - PPGSP-UFSC. Florianópolis, 2013.

CÂNDIDO, Antônio. Os Parceiros do Rio Bonito: estudo sobre o caipira paulista e as transformações em seu modo de vida. São Paulo: Duas Cidades, 1977. 
CAZELLA, Ademir Antonio. Agricultura Familiar: ainda é possível se diferenciar? Observatório de Políticas Públicas para a Agricultura nº43. Ago., 2012.

DELGADO, Nelson Giordano; LEITE, Sérgio Pereira. Gestão social e novas institucionalidades no âmbito da política de desenvolvimento territorial. in: MIRANDA, Carlos; TIBURCIO, Breno. Políticas Públicas, Atores Sociais e Desenvolvimento Territorial no Brasil. Brasília: IICA, 2011. p. 89-119.

FREITAS, Alan Ferreira de et. al. O Programa Nacional de Desenvolvimento Sustentável de Territórios Rurais: a indução de territorialidades à ação pública. Perspectivas em Políticas Públicas, v. 3, n. 6, Belo Horizonte, p. 27-58, jul./dez. 2010. p. 27-58

FOX, Jonathan. Democratic rural development: leadership accountability in regional peasant organizations. Review of Development and Change, 23 (2), 1990.

GARCIA Jr., Afrânio; GRYNSZPAN, Mario. Veredas da questão agrária e os enigmas do grande sertão. in: MICELI, Sérgio (org.). O Que Ler em Ciências Sociais. São Paulo: ANPOCS, 1999.

GAZOLLA, Márcio. Agricultura Familiar, Segurança Alimentar e Políticas Públicas:uma análise a partir da produção para o autoconsumo no território do Alto Uruguai/RS. Dissertação de mestrado - PPGDR-URGS. Porto Alegre, 2004.

GUANZIROLI, Carlos E. PRONAF dez anos depois: resultados e perspectivas para o desenvolvimento rural. Revista de Economia e Sociologia Rural vol.45 n.2, Brasília, Abr/Jun 2007.

GUIMARÃES, Alberto P. Quatro Séculos de Latifúndio. Rio de Janeiro: Paz e Terra, 1977.

MALUF, Renato. Políticas agrícolas e de desenvolvimento rural e a segurança alimentar. in: LEITE, Sérgio (org.). Políticas Públicas e Agricultura no Brasil. Porto Alegre: UFRGS, 2001.

MARTINS, José de S. Os Camponeses e a Política no Brasil. Petrópolis: Vozes, 1986.

MARTINS, José de S. O Poder do Atraso. Ensaios de sociologia da história lenta. 2 ed. São Paulo: Hucitec, 1999.

MARTINS, José de S. O Sujeito Oculto. Ordem e transgressão na reforma agrária. Porto Alegre: UFRGS, 2003.

NAVARRO, Zander. Manejo de Recursos Naturais e Desenvolvimento Rural: um estudo comparativo em quatro estados brasileiros (lições e desafios). Relatório ao Banco Mundial, 1999.

NAVARRO, Zander. Desenvolvimento rural no Brasil: os limites do passado e os caminhos do futuro. Revista Estudos Avançados, v.16, n. 2, p.83-100, nov. 2001. 
NAVARRO, Zander. Mobilização sem emancipação: as lutas sociais dos sem terra no Brasil. in: SANTOS, B. S. (org). Produzir Para Viver: os caminhos da produção não capitalista. São Paulo: Civilização Brasileira, 2002.

PETRELLI C.V.; Silva, F. O novo desenho do financiamento agrícola e as dificuldades para os produtores não integrados. Anais XVII Congresso da SOBER, Cuiabá, jul./2004.

PLOEG, Jan. Douwe Van Der et al. Rural development: from practices and policies towards theory. Sociologia Ruralis, Oxford, UK, v. 40, n. 4, p. 391-408, out. 2000.

PRADO JUNIOR, Caio. A Questão Agrária. São Paulo: Brasiliense, 1979.

SABOURIN, Eric. Que política pública para a agricultura familiar no segundo governo Lula? Sociedade e Estado v.22 n.3, Brasília, set./dez. 2007.

SCHNEIDER, Sergio; TARTARUGA, Iván G. P. Do Território Geográfico à Abordagem Territorial do Desenvolvimento Rural. Jornadas de Intercambio y Discusión: el desarrollo Rural en su perspectiva institucional y territorial. Buenos Aires: UBA- CONICET, 2005.

SCHNEIDER, Sérgio. Situando o desenvolvimento rural no Brasil: o contexto e as questões em debate. Revista de Economia Política, vol. 30, nº3. p. 511-31, jul./set. 2010.

SILVA, Newton J. R. da. Dinâmicas de Desenvolvimento da Piscicultura e Políticas Públicas no Vale do Ribeira/SP e Alto Vale do Itajaí/SC - Brasil. Tese de doutorado UNESP. São Paulo, 2005.

SILVA, José Gr. da. Tecnologia e Agricultura Familiar. 2 ed. Porto Alegre: Editora da UFRGS, 2003.

SOUZA, Rômulo V. C. C. de et al. O acesso às inovações nos sistemas da agricultura familiar tradicional e em assentamentos da reforma agrária. in: I Encontro da Rede de Estudos Rurais. Rio de Janeiro, 2006. 